\title{
Electroconvulsive therapy: Effect of an educational experience on nursing students' knowledge and attitudes
}

\author{
Eman Dawood ${ }^{1,2}$, Abeer Selim ${ }^{2,3}$, Amal Khalil ${ }^{1,4}$ \\ 1. Psychiatric Mental Health Nursing Department, College of Nursing, Menofyia University, Shebin El-Kom, Egypt. \\ 2. Psychiatric and Mental Health Nursing, College of Nursing, King Saud bin Abdulaziz University for Health Sciences, \\ Riyadh, Kingdom of Saudi Arabia. 3. College of Nursing, Psychiatric Mental Health Nursing Department, Mansoura \\ University, Mansoura, Egypt. 4. Psychiatric and Mental Health Nursing, College of Nursing, King Saud bin Abdulaziz \\ University for Health Sciences, Jeddah, Kingdom of Saudi Arabia.
}

Correspondence: Eman Salah Dawood. Address: College of Nursing, Riyadh (MC: 3105), King Saud Bin Abdul Aziz University for Health Sciences, P.O. Box 3660 Riyadh 11481, Kingdom of Saudi Arabia. Telephone: 96-615-9828-6162. Email: dawoode@ksau-hs.edu.sa.

Received: November 25, 2012

Accepted: January 27, 2013

Online Published: March 14, 2013

DOI : $10.5430 /$ jnep.v3n9p123

URL: http://dx.doi.org/10.5430/jnep.v3n9p123

\begin{abstract}
Objective: Despite the proved effectiveness of Electroconvulsive therapy (ECT) in the treatment of many psychiatric emergencies and disorders, there are many misconceptions and groundless negative attitudes about its prescription and utilization by many health professionals. The purpose of this study was to determine the effect of an educational experience including a two hours lecture on ECT and viewing a video of the ECT procedure on nursing students' knowledge of and attitudes towards ECT.
\end{abstract}

Methodology: A quasi experimental research design was used to conduct the current study. A 28 - items (two constructs measuring students' attitudes and knowledge) self administered questionnaire was administered before and after exposure to the two - hour lecture and a movie representing the ECT procedure to a non probability convenience sample of ninety seven female nursing students. Informed written consent was obtained from all students who agreed to participate in the study.

Results: Paired sample T. test showed significant differences in students' scores before and after their educational experience in the psychiatric/mental health nursing course as following: attitude scores $(t=20.507, P<.000)$ knowledge score $(t=20.697, p<.000)$ and the total scale score $(t=23.849, p<.000)$. No statistically significant differences in the mean knowledge or attitude scores between those students who had a past experience with a person with a diagnosis of mental health problem and those students who did not have such past experience.

Conclusion: Positive educational experiences would increase the knowledge of ECT, which might in turn contribute to more favorable attitudes towards ECT. Proper educational materials and mass media programs aiming to increase students and practitioners' awareness about ECT are recommended.

\section{Key words}

Electroconvulsive therapy, Nursing students, Attitude, Knowledge, Educational experience 


\section{Background}

Electroconvulsive therapy (ECT) involves the induction of a grand mal seizure through the passage of an electrical current to the patient brain with the aim of improving the patients' mental status under anesthesia and muscle relaxant ${ }^{[1]}$. There is no solid based clarification for the mechanism of action and how the ECT works but the most credibility goes to the biochemical theory ${ }^{[1-3]}$. ECT was first introduced into psychiatry more than seven decades back in 1938 in Rome by an Italian neuropathologist and psychiatrist Ugo Cerletti ${ }^{[4,5]}$. ECT is widely prescribed worldwide and first indicated in the emergency treatment of severe depression with suicide or psychosis, medication - resistant schizophrenia ${ }^{[3]}$. Effectiveness of ECT in the treatment of depression was established in $1941^{[7]}$. The introduction of psychopharmacology in the 1970s and 1980 reduced the use of ECT in the treatment of mental illnesses ${ }^{[6]}$.

Modified and non - modified ECT are the two forms of the treatment, modification comes in the form of using anesthesia together with muscle relaxant to limit the intensity of convulsion and reduce its side effects as bone and teeth fractures, muscular and tendon damage. Most of the internationally established guidelines recommended the modified ECT in the last decade $(1990-2000)$ as the slandered routine treatment ${ }^{[8-10]}$. Unilateral treatment is prescribed for some patients instead of bilateral treatment to overcome the most frequently occurring side effects as temporary memory loss, mental confusion and headache, while permanent cognitive impairment remains obscure. Despite the documented effectiveness of the ECT in the treatment of symptoms of depression ${ }^{[1]}$, from the prospective of many professionals and public, ECT still remains controversial and stigma bounded. Attending the life treatment session plays significant role in forming attitudes towards ECT while viewing movies' clips that portraying ECT as an inhuman and brutal method generates a more negative attitude towards $\mathrm{ECT}^{[12]}$.

Today's nursing students are tomorrow's nurses who will be closely working and taking care of the patients. The nature of nursing profession requires nurses to spend more hours with the patients than all other health care professionals and considering the valuable and essential nursing interventions provided to the patients undergoing ECT prior, during and after the treatment session; therefore, nurses' knowledge and attitudes towards ECT will impact their patients' knowledge and attitudes towards ECT ${ }^{[13]}$. Literature review reveals several studies exploring nurses' knowledge and attitudes towards $\mathrm{ECT}^{[13]}$. It has been suggested that there is a positive relationship between years of clinical experience and knowledge of mental health professionals regarding ECT and their attitudes towards ECT, while poor contact with ECT during students training was connected to poor knowledge and more negative attitudes ${ }^{[13,14]}$.

Because of the dramatic increase of the nursing students enrolled in many nursing schools and the inadequate patients' number undergoing ECT that limit every student chance to attend a live ECT treatment session, alternative educational materials have been introduced to inform students about ECT as lectures, pamphlets and real and simulated video scenes. However, the literature reveals a paucity of published studies concerning knowledge and attitudes towards ECT on the Saudi Arabian national level.

The aim of the present study was to explore the effect of educational experiences on the knowledge and attitudes towards ECT among nursing students.

\section{Objectives of the study}

The objective of the current study was to:

1) Compare nursing students' knowledge and attitudes towards ECT before versus after completing the theoretical and practical parts of a psychiatric nursing course related to ECT.

2) Investigate the association between the knowledge of and attitudes towards ECT.

3) Examine the relationship between students' knowledge of, attitudes towards ECT and their personal experience with a person with a mental health problem. 


\section{Subjects and methods}

\subsection{Design}

Quasi experimental research design was used to conduct this study with the aim to assess the impact of 2 - hours educational session about ECT on the knowledge of and attitudes towards ECT among nursing students.

\subsection{Setting}

The study was conducted in the College of Nursing (CON - R), King Saud Bin Abdulaziz University for Health Sciences - Riyadh (KSAU - HS).

\subsection{Participants}

A non-probability convenience sample consisted of one hundred and fourteen nursing students enrolled in the psychiatric/ mental health nursing course for the academic year 2011-2012 were invited to participate in the study. 97 students agreed to participate in the study and completed both the pre and post experience survey giving a response rate of $85 \%$.

Forty five students were enrolled in the fall semester and 52 students were enrolled in the spring 2012 semester. Students were verbally invited to participate in this study. The structured ECT educational session was a fundamental part of the theoretical and clinical curriculum and composed of two hours clinical seminar (outlines included: ECT definitions, indications, contraindications, mechanism of action, side effects and serious complications, the treatment procedure, and nursing interventions prior, during and after the ECT procedure) and watching video scenes representing the ECT procedure.

\subsection{Data collection tools}

Data were collected using a modified version of the questionnaires on knowledge of and attitudes towards ECT ${ }^{[15,16]}$. One statement concerning attitude towards ECT was added and six statements concerning the complications of ECT, physical and psychological preparation of the patient were also included. The final questionnaire consists of 28 - items (see Table $1)$, which were self administered rated on a Likert type scale of 1-3 $(1=$ disagree, $2=$ do not know, $3=$ agree $)$. The questionnaire items included 14 statements concerning attitudes towards ECT ${ }^{[1-16]}$ and 14 statements concerning the students' knowledge about ECT ${ }^{[8,9,17-28]}$. Six attitudinal statements were scored positively (higher scores indicating more positive attitudes) while eight statements were scored in reverse way. Of the knowledge statements six statements were scored in a positive way with higher scores reflecting accurate knowledge, eight statements were scored in negative way with disagree indicating the accurate response. The total possible score range between 28 and 84 with higher scores indicating more knowledge and more positive attitudes towards ECT (see Table 1).

The other part of the questionnaire included questions regarding students' age, sources of knowledge about ECT, indications of ECT, and if the nurse student had any personal experience with a person with a diagnosis of mental health problem other than from the clinical setting.

Content validity of the instrument was assessed by two experts who examined the tool and approved it. Test retest method was used to determine the reliability of the tool, by applying this tool twice on 10 subjects who were excluded from the study. The reliability was 0.86 . Subjects needed $15-20$ minutes to complete the questionnaire. A pilot study was conducted to test the feasibility and applicability of the tool. The pilot study was carried out on five subjects. The result of the pilot study was help in refining the questionnaire form.

\subsection{Ethical issues}

Informed written consent was obtained from the students who agreed to participate in the study. Participants completed the survey questionnaire on the first day of their clinical placement and again completed the same questionnaire after 
completing the part of the course related to the ECT topic. Anonymity was ensured by using identification codes on the questionnaires that facilitated individual comparison of pre and post clinical placement responses. It was clearly stated that students' participation is voluntary and confidential and that the responses would not in any way impact their final grades of the concerned course, in addition, students were assured about their right to withdraw from the study at any time.

Table 1. Students' knowledge of and attitudes towards Electroconvulsive therapy

For each of the following statements, please indicate how much do you agree or disagree

\begin{tabular}{|c|c|c|c|}
\hline Statement & Agree & Do not Know & Disagree \\
\hline ECT is primitive method of treatment & 1 & 2 & 3 \\
\hline ECT is outdated and should never be used & 1 & 2 & 3 \\
\hline ECT is inhuman treatment & 1 & 2 & 3 \\
\hline ECT is painful & 1 & 2 & 3 \\
\hline ECT should only be used in serious or life threatening situations & 1 & 2 & 3 \\
\hline ECT should only be used as a last treatment choice & 1 & 2 & 3 \\
\hline ECT can be life saving for some patients & 3 & 2 & 1 \\
\hline ECT can get patients better more quickly than antidepressants & 3 & 2 & 1 \\
\hline There is no scientific evidence that ECT is effective & 1 & 2 & 3 \\
\hline ECT is given as a punishment to violent/angry patients & 1 & 2 & 3 \\
\hline Some patients agree to have ECT & 3 & 2 & 1 \\
\hline I would agree to have ECT if I were depressed & 3 & 2 & 1 \\
\hline I would recommend ECT to a family member if it is recommended & 3 & 2 & 1 \\
\hline I feel comfortable watching ECT being administered & 3 & 2 & 1 \\
\hline I would feel comfortable administering ECT if I had received the proper training & 3 & 2 & 1 \\
\hline ECT is an embarrassing experience contributes to the stigma of mental illness & 1 & 2 & 3 \\
\hline ECT should be administered without obtaining patient' informed consent & 1 & 2 & 3 \\
\hline ECT should be given only on inpatient hospital setting & 1 & 2 & 3 \\
\hline ECT can be given to pregnant woman & 3 & 2 & 1 \\
\hline ECT can be given to older persons & 3 & 2 & 1 \\
\hline Use of ECT leads to permanent loss of memory & 1 & 2 & 3 \\
\hline Use of ECT leads to temporary impairment of memory & 3 & 2 & 1 \\
\hline Use of ECT causes permanent brain damage & 1 & 2 & 3 \\
\hline Use of ECT causes burns & 1 & 2 & 3 \\
\hline Use of ECT causes death & 1 & 2 & 3 \\
\hline ECT can be performed without anesthesia & 3 & 2 & 1 \\
\hline Physical care of patients undergoing ECT is important & 3 & 2 & 1 \\
\hline Psychological care of patients undergoing ECT is essential & 3 & 2 & 1 \\
\hline
\end{tabular}

\subsection{Data analysis}

The data were coded and analyzed using SPSS version 18.0. A paired $t$ test was used to analyze the total scores of students before and after the course, furthermore, each specific question was analyzed separately with the same method. Betweengroup sociodemographic and attitudinal differences were analyzed using non probability Chi Square test $\left(\chi^{2}\right)$. Pearson $r$ was used to test correlation. The significance level was chosen as $(p<0.05)$. Data was presented using descriptive statistics in the form of frequencies and percentages. Interval and ratio variables were presented in the form of means and standard deviations.

\section{Results}

Participants' age ranged between 20 to 30 years with a mean age of 22.73 ( $\mathrm{SD} \pm 2.38$ ). Majority of the students were stream one (traditional, high school graduates) students $(n=77,79.4 \%)$ while only twenty students $(20.6 \%)$ were enrolled 
in the program as stream two students (accelerated, recently held another bachelor degree in science). With respect to any information about ECT, 89 (91.8\%) of the subjects had previously heard about ECT while only eight students (8.2\%) had never heard of ECT before enrolling into the psychiatric nursing class.

Regarding the sources of knowledge about ECT, students referred their information to the movies as the main source ( $\mathrm{n}=$ $56,57.7 \%)$ followed by discussion in a college class $(n=35,36.1 \%)$, television shows $(n=28,28.9 \%)$, other sources of information included discussion with friends or colleagues, reading books or internet resources respectively, and only one student gained information regarding ECT from a personal experience with a family member undertook ECT treatment (see Table 1). About quarter of the subjects included in the study had known someone with a mental health problem other than in the clinical area during the course $(n=27,27.8 \%)$ while the majority of the participants were never exposed to any experience with a person with a mental health problem $(n=70,72.2 \%)$.

Table 2. Sources of students' knowledge about ECT $(n=97)$

\begin{tabular}{lll}
\hline Source of Knowledge & $\mathbf{N}$ & $\mathbf{\%}$ \\
\hline Movies / Film / Series & 56 & 57.7 \\
College class & 35 & 36.1 \\
TV program & 28 & 28.9 \\
Discussion with family member/ friend/ colleague & 18 & 18.6 \\
The Internet & 15 & 15.5 \\
Books & 11 & 11.3 \\
Newspaper / Magazine & 5 & 5.2 \\
Personal experience & 1 & 1 \\
\hline
\end{tabular}

In assessing students' knowledge regarding the indications on ECT before their educational experience, results of the current study revealed that students believed that ECT is mainly indicated for the treatment of depression $(\mathrm{n}=52)$ followed by schizophrenia $(n=48)$, then the treatment of patients with diagnoses of bipolar disorders $(n=40)$, anxiety and anxiety related disorders $(n=22)$ and only 18 students believed that ECT is used for the treatment of substance related disorders, seven students added aggression and suicide as other indications to ECT.

Students' total pre - experience minimum knowledge of ECT score was 40 and the maximum pre - experience total scale score was $72($ Mean $=55.44, \mathrm{SD} \pm 7.18)$ while the reported students' total post - experience minimum scale score was 58 and the maximum post - experience total score was 82 (Mean $=74.85, \mathrm{SD} \pm 5.37$ ). With regard to the attitude construct , data analysis showed that students' total pre - experience attitude score ranged between 16 and 38 with a Mean score of $26.28, \mathrm{SD} \pm 4.26$, that score raised after the experience to 27 as the lowest post - experience attitude score and 41 as the highest post - experience attitude score (Mean $=35.61, \mathrm{SD} \pm 3.37)$.

Table 3. Students' knowledge about indications of ECT $(n=97)$

\begin{tabular}{lll}
\hline Indication & N & \% \\
\hline Depression & 52 & 53.6 \\
Bipolar disorders & 40 & 41.2 \\
Schizophrenia & 48 & 49.5 \\
Substance related disorders & 18 & 18.6 \\
Anxiety related disorders & 22 & 22.7 \\
\hline
\end{tabular}

Results showed improvement in the student's knowledge after completing the educational experience as revealed by the mean knowledge score pre and post experience improvement (29.16 $\mathrm{SD} \pm 4.06$ and $39.21 \mathrm{SD} \pm 2.67$ ) respectively.

Participants' attitudes and knowledge scores before and after ECT experience are presented in Table 4. Paired sample $t$. test indicated significant differences in students' scores before and after their experience in the psychiatric/mental health nursing course as follows: attitude scores $(P<.001)$ knowledge score $(t=p<.001)$ and the total scale score $(p<.001)$ 
Independent sample $t$ test revealed no statistically significant differences in the mean knowledge or attitude scores between those students who had a past experience with a person with a diagnosis of mental health problem and those students who did not have such past experience.

Table 4. Nursing students' pre and post experience ECT attitudes and knowledge scores $(n=97)$

\begin{tabular}{|c|c|c|c|c|c|c|}
\hline & \multicolumn{2}{|c|}{ Pre - Experience } & \multicolumn{2}{|c|}{ Post Experience } & \multicolumn{2}{|c|}{ Test of Significance } \\
\hline & Mean & SD & Mean & SD & $t$ & $P$. Value \\
\hline Attitude Score & 26.28 & 4.26 & 35.61 & 3.37 & 20.507 & 0.000 \\
\hline Knowledge Score & 29.16 & 4.06 & 39.2 & 2.67 & 20.697 & 0.000 \\
\hline Total Score & 55.44 & 7.18 & 74.85 & 5.37 & 23.849 & 0.000 \\
\hline
\end{tabular}

Table 5. Impact of Having Past Experience with a Person with a Mental Illness on Different Test Scores $(n=97)$

\begin{tabular}{|c|c|c|c|c|c|c|}
\hline \multirow{3}{*}{ Item } & \multicolumn{4}{|c|}{$\begin{array}{l}\text { Having Past Experience with a Person with a } \\
\text { Mental Illness }\end{array}$} & \multirow{2}{*}{\multicolumn{2}{|c|}{ Test of Significance }} \\
\hline & \multicolumn{2}{|l|}{ Yes } & \multicolumn{2}{|l|}{ No } & & \\
\hline & Mean & SD & Mean & SD & $t$ test & $P$ Value \\
\hline Pre Educational Experience Knowledge Score & 30.30 & 4.23 & 28.73 & 3.93 & -1.72 & 0.08 \\
\hline Post Educational Experience Knowledge Score & 38.44 & 3.45 & 39.50 & 2.25 & 1.77 & 0.08 \\
\hline Pre Educational Experience Attitude Score & 27.19 & 4.53 & 25.93 & 4.14 & -1.31 & 0.19 \\
\hline Post Educational Experience Attitude Score & 35.37 & 4.26 & 35.70 & 2.99 & 0.43 & 0.67 \\
\hline Pre Educational Experience Total Scale Score & 57.48 & 7.57 & 54.66 & 6.92 & -1.76 & 0.08 \\
\hline Post Educational Experience Total Scale Score & 73.93 & 7.11 & 75.20 & 4.55 & 1.05 & 0.29 \\
\hline
\end{tabular}

To investigate the association between students' knowledge and attitudes towards ECT, Pearson Correlation revealed positive relationship between student knowledge and attitudes both before and after their experience $(r=0.50, P<0.001$, $r=0.56, p<0.001)$ respectively. This finding indicated that the more information the student had, the more positive attitude they held. With regard to the total scale score, data analysis showed that there was a positive relationship between the knowledge and the attitude scores $(r=0.21, p<0.05)$, this finding signified the contribution of the educational experience about ECT to the improvement of the students' knowledge and consequently their attitude.

\section{Discussion}

Consistent with the findings of Warnell et al. ${ }^{[14]}$ and Onesirosan et al. ${ }^{[17]}$, key sources of students' information were movies followed by discussion in a college class and then TV programs. Media in the majority of Arab world represent mental illnesses and mental treatments in a more negative way which result in poor knowledge and more negative attitudes towards psychiatry ${ }^{[18]}$ and consequently towards ECT as one of the psychiatric treatment options before the educational experience.

Findings of this study suggested that there is an obvious improvement in terms of knowledge and attitudes towards ECT after the students go through the educational experience consisting of a two hours lecture on ECT and viewing a video of the ECT procedure. This finding is consistent with the study by Poster, et al. ${ }^{[19]}$ who concluded that teaching nursing students using a videotape on ECT had a positive impact on nursing students' perception of ECT. Warnell et al. ${ }^{[14]}$ also concluded that watching live demonstration or viewing an ECT videotape was effective ECT teaching methods for students who had positive impact on the students' knowledge and attitudes towards ECT. Szuba et al ${ }^{[20]}$ and Chanpat$\operatorname{tana}^{[21]}$ also observed the positive effect of psychiatry training in improving levels of knowledge about ECT among students.

Interestingly, results of the current study revealed that having past experience with a person diagnosed with a mental health problem had no significant impact both on the knowledge and on the attitudes towards ECT. This finding might be 
explained by the fact that only 17 students had past experience with a person with a diagnosis of mental health problem and that only one student of those seventeen refereed to her past experience as a source of information about ECT. No studies have been found in the literature that linked the personal past experience with knowledge and attitudes towards ECT among nursing students.

\section{Limitations of the study}

One limitation of this study is that the participants were aware of the researcher interests, which could have affected some of the responses in a way that they thought would be desirable or more socially acceptable. Another limitation is that the study was carried out in one single institution, used internal controls (before versus after educational experience within the same group of students) rather than comparison with external controls, which limits the generalization of the findings of this study. Additional limitation is that we assessed the knowledge and attitudes right after the educational experience within the same session which cannot predict students' attitudes over time.

\section{Conclusions}

As it is proven that knowledge is a predetermining of attitudes, so providing and expanding accurate knowledge about ECT is necessary in order to improve the attitudes towards ECT. Nursing students' knowledge and attitudes towards ECT will be conveyed to their patients during their clinical practice and then during their future career as nurses; hence, improving nursing students' knowledge and attitudes might enhance psychiatric patients' attitudes towards ECT. Results of the current study signify the importance to present the up - to - date scientific basis of ECT when teaching nursing students about ECT.

\section{Recommendations for future research}

1) Replication of the current study using a larger sample size and multiple settings.

2) Investigating other issues that might contribute to poor attitudes towards ECT such as cultural issues.

3) Developing a standardized culturally - sensitive tool to assess attitudes towards ECT.

4) Inclusion of qualitative research methodology may expand the understanding of the studied subject.

\section{Acknowledgment}

Researchers would like to extend their thanks and appreciations to all College of Nursing students, affiliated to King Saud Bin Abdulaziz University for Health Sciences, Riyadh, who agreed to participate in this study and shared their experiences.

\section{References}

[1] Varcarolis, E., Halter, M. J. Foundations of Psychiatric Mental Health Nursing. A clinical approach. 6th ed. Elsevier, Saunders 2011.

[2] Fink, M. Convulsive Therapy: A review of the first 55 years Journal of Affect. Disorder. 2001; 63: 1-15. http://dx.doi.org/10.1016/S0165-0327(00)00367-0

[3] Townsend, M.C. Essentials of Psychiatric Mental Health Nursing, 5th ed. Philadelphia. F. A. Davis Company 2011.

[4] Cerletti,U., Bini, L. Un nouvo metodo di shockerapie: 'l' elettroshock' (riassunto). Reale Accedemia Medica (Communicazione alla seduta del 28 maggio 1938-XVI della Reale Accademia Medica Di Roma.) Rome 1938.

[5] Fink, M. Convulsive therapy: Theory and practice. Raven Press, New York 1979, 306.

[6] McCall, W. V. Electroconvulsive therapy in the era of modern psychopharmacology. Int. J. Neuropsychop. 2001 ; 4: 315-324. 
[7] Hemphill, K. E., Walter, W. G. The treatment of mental disorders by electrically induced convulsions. J. Ment. Sci.1941; 87: 256 275.

[8] American Psychiatric Association. in: R. D. Weiner, ed. The practice of Electroconvulsive Therapy: recommendation for treatment, training, and privileging: a task force report of the American Psychiatric Association. The American Psychiatric Association VII, Washington, DC. 2001; p. 355.

[9] Royal College of psychiatrists. The handbook: the third report of the Royal College of Psychiatrist's Special committee on ECT. Royal college of Psychiatrists, London, xii, 2005; 243.

[10] Enns, M. W., Riess, J. P., Chan, P. Electroconvulsive therapy. [Position Paper 1992-27-R1]. Can. J. Psychiatry. 2010; 55: 1-12. Available from: http://publications.cpa-apc.org/media.php?mid=978 (accessed January, 13, 2011).

[11] The UK ECT Review Group. Efficacy and safety of electro-convulsive therapy in depressive disorders: a systematic review and meta-analysis. Lancet. 2003; 361: 799-808. http://dx.doi.org/10.1016/S0140-6736(03)12705-5

[12] Walter, G., McDonald, A., Rey, JM. et al. Medical student knowledge and attitudes regarding ECT prior and after viewing ECT scenes from movies. J. ECT. 2002; 18: 43 - 46. http://dx.doi.org/10.1097/00124509-200203000-00012

[13] Wood, J. H., Chambers, M. D., White, S. J. Nurses' Knowledge of and Attitude to Electroconvulsive Therapy. J. ECT. 2007; 23 (4): 251-254. PMid:18090698 http://dx.doi.org/10.1097/yct.0b013e31813e0692

[14] Warnell, R., Duk, A.D., Christian G.W., Havilland, M., G. Teaching Electroconvulsive Therapy to Medical Students: Effect of instructional method on knowledge and attitude. Acad Psychiatr. 2005; 29: 443-436. PMid:16387965 http://dx.doi.org/10.1176/appi.ap.29.5.433

[15] Chavan, B. S., Kumar, S., Arun, P., Bala, C., Singh, T. ECT: Knowledge and Attitude among patients and their relatives. Indian J Psychiatry. 2006; 48 (1): 34 - 38. PMid:20703412 http://dx.doi.org/10.4103/0019-5545.31616

[16] Kinnair, D., Dawson, S., Perera, R. (2010). Electroconvulsive Therapy: Medical Students' Attitudes and Knowledge. The Psychiatrist. 2010; 34: 54 - 57. http://dx.doi.org/10.1192/pb.bp.108.023358

[17] Bawo Onesirosan, J., Omoaregba, J., Olotu, O. Nigerian Medical Students Attitudes to Unmodified Electroconvulsive Therapy. J. ECT. 2009; 25(3):186-189. PMid:19057398 http://dx.doi.org/10.1097/YCT.0b013e31818c7701

[18] Dawood, E. Impact of Clinical Placement on Nursing Students' attitudes toward Psychiatry. J Am Sci. 8 (2): 627 - 632.

[19] Poster E., Boxter L. R., Hammon C. L. Nursing students. Perception of electroconvulsive therapy: impact of instruction with an electroconvulsive therapy videotape. Convuls. Ther. 1985; 1: 277 - 282. PMid:11940834

[20] Szuba M., Guze BH., Liston EH., et al. Psychiatric resident and medical student perspectives on ECT: Influence of exposure and medication J. ECT 1992; 8: 110-117.

[21] Chanpattana W. ECT knowledge in psychiatrists, psychiatry residents, and medical students: effect of training. J. Med. Assoc. Thai. 1999; 82: 819 - 825. PMid:10511792 